\title{
Modelo integrado de apoio ao planejamento da rede de serviços no transporte ferroviário de cargas: aplicação para transporte de minério de ferro
}

\author{
Luciano Bandeira Campos'; Marta Monteiro da Costa Cruz²; \\ Fabiano Mezadre Pompermayer ${ }^{3}$
}

\begin{abstract}
Resumo: Apresenta-se um modelo de otimização para auxiliar o planejamento tático ferroviário com visão integrada da rede (operações em linha e pátios), e que foi aplicado ao transporte de minério de ferro numa conhecida ferrovia brasileira, considerando o efeito congestionamento. O problema é de programação não linear inteira, e a solução foi obtida por um aplicativo computacional disponível no mercado. O objetivo é facilitar o planejamento da rede de serviços: quais trens (serviços) devem ser operados, sua frequência, e a sequência recomendada das operações e serviços desde a origem das cargas até o destino. A pesquisa de literatura identificou um modelo que, mediante adaptações, foi aplicado ao fluxo de trens com diferentes opções preestabelecidas de configuração, desde 11 pontos de origem até um terminal exportador e passando por três pátios intermediários, onde os trens podem ser combinados entre si. Os resultados variam conforme a abordagem adotada para a função objetivo, com diferenças significativas na frequência dos diversos serviços disponíveis e no uso dos pátios intermediários.
\end{abstract}

Abstract: This paper presents an optimization model developed to help tactical planning at railroads with an integrated view of the network (line and yard operations). The model was applied to iron ore transportation in a well-known Brazilian railroad, considering congestion effects. This is an integer nonlinear problem, which was solved by an optimization package. The objective is to help decision making related to service network design: which trains (services) should run, how frequently and what should be the recommended sequence of activities to be performed at intermediate yards from origin to destination of cargo. Literature research identified a model that could be modified and adapted to the flow of different predefined train consist options, which are operated from 11 mines toward an export terminal. Three intermediate rail yards may be used to combine train consists. Results are presented and vary according to the objective function approach, with relevant differences in service frequencies as well as in the use of intermediate rail yards.

\section{INTRODUÇÃO}

O modo ferroviário exige altos investimentos para instalação, operação e manutenção de seus recursos (vias de circulação, pontes, viadutos, túneis, pátios ferroviários, oficinas, vagões e locomotivas). Por outro lado, um aspecto de destaque é sua alta eficiência energética, o que o torna competitivo no transporte de carga por longas distâncias, apresentando consumo de combustível relativamente baixo, principalmente quando comparado ao modo rodoviário (Magalhães, 2001).

Apesar da reconhecida eficiência energética, o gasto com combustível tem participação considerável no custo variável das ferrovias, o que as têm levado a buscar boas práticas operacionais para redução do consumo de combustível.

A gestão eficaz da alocação dos ativos em uma ferrovia é um desafio e requer amplo planejamento das operações nos níveis estratégico, tático e operacional.

${ }^{1}$ Luciano Bandeira Campos, Programa de Pós-Graduação em Engenharia Civil, Universidade Federal do Espírito Santo, Vitória, ES, Brasil. (e-mail: lucianobcampos@gmail.com).

${ }^{2}$ Marta Monteiro da Costa Cruz, Departamento de Engenharia de Produção, Universidade Federal do Espírito Santo, Vitória, ES, Brasil. (e-mail: mcruz@npd.ufes.br).

${ }^{3}$ Fabiano Mezadre Pompermayer, Instituto de Pesquisa Econômica Aplicada, Rio de Janeiro, RJ, Brasil. (e-mail: fabiano.pompermayer@ipea.gov.br).

Manuscrito recebido em 7/12/2009 e aprovado para publicação em 15/3/2010. Este artigo é parte de TRANSPORTES, volume XVIII, número 2, junho de 2010. ISSN: 2237-1346 (online).
O planejamento bem feito melhora o desempenho das ferrovias, o que justifica o desenvolvimento de ferramentas de apoio à decisão. Assad (1980a) expõe vários aspectos decisórios em ferrovias, caracterizadas como complexos sistemas com diversos processos inter-relacionados. Decisões sobre processos nos terminais, por exemplo, poderão ter efeitos sobre os processos na vias de circulação e vice-versa.

Decisões do dia a dia são suportadas por um planejamento de médio prazo (tático), o qual frequentemente utiliza informações em um nível mais agregado e possui alcance sobre toda a ferrovia. Este planejamento define, por exemplo, a escolha dos trens a serem operados (tamanho, trajeto e frequência), a definição do roteiro das cargas e a sequência de trens e operações a serem feitas nos terminais desde a origem até o destino da carga (Crainic et al., 1984).

Propõe-se investigar o processo decisório acima, fazendo-se uma aplicação ao fluxo de exportação em uma ferrovia que faz parte da cadeia de suprimentos do minério de ferro. A ferrovia pertence a uma conhecida mineradora brasileira e faz amplo uso de trens com minério em diferentes opções de configuração preestabelecidas, entre 11 pontos de carregamento situados próximos das minas e um terminal portuário exportador, passando por três pátios intermediários onde as composições ferroviárias podem ser combinadas entre si. Optou-se por uma modelagem com enfo- 
que no uso eficaz da frota e no consumo de combustível.

O problema observado na ferrovia em questão diz respeito à definição do "mix" de trens a serem operados na malha. Esta decisão tem sido dificultada na medida em que, graças ao avanço tecnológico, alternativas de tipos de formação de trem se multiplicaram. É possível, por exemplo, optar entre operar com trens curtos (mais frequentes), ou com trens longos. Cada alternativa de configuração do trem é denominada serviço ou trem típico, com características próprias (carga transportada, pátios de origem e destino do trem, consumo de combustível, número de locomotivas e vagões transportados). Outra questão a ser considerada diz respeito à escolha entre trens diretos desde a origem ao destino da carga ou trens que sofram consolidações ao longo do trajeto (trens indiretos).

A proporção entre as diversas opções de trens tem profunda repercussão no desempenho da ferrovia como um todo. Optar por trens curtos, por exemplo, pode implicar em uma malha mais congestionada devido ao maior número de trens na malha. Trens longos por outro lado, reduzem o congestionamento nas vias de circulação e melhoram a eficiência no consumo de combustível, mas suas manobras de formação fazem com que o material rodante fique retido por mais tempo nos pátios ferroviários, o que também ocorre com trens que não são diretos.

Portanto, o objetivo deste trabalho é desenvolver um modelo de otimização para auxílio ao planejamento tático integrado do fluxo de trens carregados destinados ao porto, considerando as operações e o congestionamento em linha e nos pátios intermediários. Serão determinadas as frequências das diversas opções de trens típicos, a partir de uma demanda de transporte, restrições e uma função objetivo. A solução deverá ainda especificar para cada ponto de carregamento: as sequências de trens típicos e operações nos pátios ferroviários (cada sequência corresponde a um itinerário possível para a carga), bem como os volumes de carga

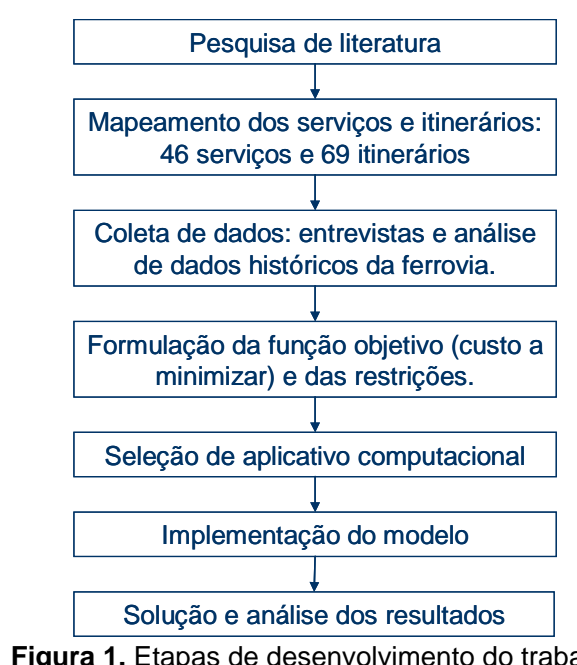

Figura 1. Etapas de desenvolvimento do trabalho movimentados em cada itinerário até o terminal exportador. As etapas de desenvolvimento deste trabalho estão apresentadas na Figura 1.

\section{REVISÃO DE LITERATURA}

O presente trabalho baseia-se em Campos et al. (2010) e Campos (2009). O problema descrito envolve o fluxo de trens sobre uma malha ferroviária, o que direcionou a pesquisa para metodologias de resolução baseadas na modelagem de fluxos em redes de maneira geral. Para esse tema, as principais referências nos aspectos teóricos foram Goldbarg e Luna (2000) e Ahuja et al. (1993). Aplicações práticas com uso de planilhas eletrônicas são desenvolvidas por Ragsdale (2007).

\subsection{Redes de transportes}

Para redes de transporte, Crainic (2003) apresenta ampla revisão das questões e modelagens relacionadas ao planejamento e gestão do transporte de cargas em longa distância, sem restringir-se a um modo de transporte específico. A abordagem concentra-se na aplicação de técnicas de pesquisa operacional a diversas esferas de decisão em transportes. São discutidas modelagens para problemas de âmbito estratégico, tático e operacional.

Segundo Crainic (2003), uma rede de transportes pode ser representada mediante o uso de grafos, sob duas formas: a rede física propriamente dita, e a rede de serviços (no caso da ferrovia, os trens e operações nos terminais). A Figura 2 ilustra esta modelagem para a aplicação ferroviária aqui proposta, em que os arcos na rede física representam as vias de circulação, ao passo que os arcos na rede de serviços representam diferentes tipos de serviços ou trens possíveis. Em ambos os grafos, nós representam pátios ferroviários.

Na Figura 2, os nós A e B representam pontos de origem das cargas, as quais são destinadas ao nó D. O nó C é um pátio intermediário onde são efetuadas manobras de recomposição dos trens. Sobre a rede física, há várias formas de operacionalizar o fluxo de cargas. Assim, cargas originadas em B podem chegar a D através de cinco itinerários possíveis (sequências de serviços e operações da origem até o destino da carga): S0-S3, S0-S4, S1-S3, S1-S4 ou diretamente, através do trem típico S2. Nota-se também que um mesmo serviço pode atender a vários itinerários. A abordagem acima é adotada por Crainic et al. (1984), cujo modelo foi adaptado para o caso estudado. 


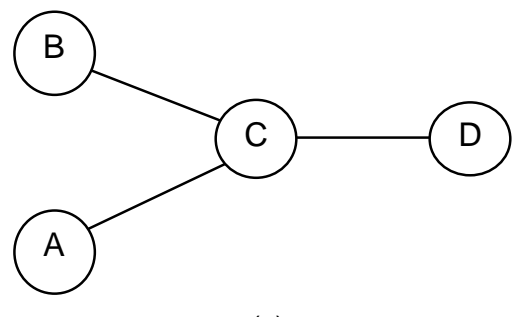

(a)

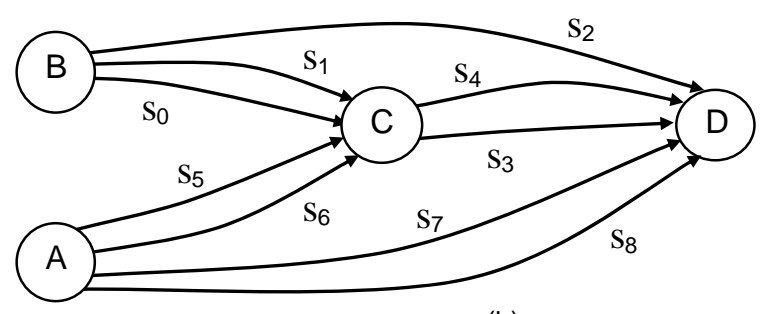

(b)

Figura 2. Exemplo de rede física (a) e a correspondente rede de serviços (b)

\subsection{Problemas clássicos no planejamento do transporte ferroviário}

Problemas de fluxos em ferrovias são tratados por Assad (1980a), referência bastante citada no tocante a modelos para tomada de decisão específicos desse modal. Conceitos e processos típicos do planejamento das operações são apresentados; estudos e modelos são agrupados e categorizados, permitindo uma visão abrangente do processo decisório. Newman et al. (2002) oferecem uma visão abrangente dos problemas de otimização no modal ferroviário e uma revisão de literatura mais recente da modelagem dos diversos tipos de problemas.

No transporte ferroviário de cargas, frequentemente os vagões são reorganizados e classificados em pátios de manobra intermediários entre a origem e o destino da carga. Nesses pátios, vagões de diferentes procedências podem ser agrupados em um bloco (grupo de vagões que se deslocam juntos por uma ou mais partes da viagem) e alocados a um mesmo trem para percorrerem trajetos comuns até novos pátios adiante, onde operações de reclassificação serão necessárias para separar vagões com destinos diferentes. Tal procedimento de consolidação permite maior aproveitamento da capacidade de tração das locomotivas e contribui para a redução do número de trens necessários ao transporte. A definição dos vagões a serem agrupados em um bloco e os reagrupamentos possíveis ao longo da viagem caracterizam o problema da blocagem .

Com relação a decisões de roteamento, podem ser consideradas sob dois aspectos: roteamento dos trens e roteamento da carga, mais explicitamente descritas por Crainic et al. (1984). Enquanto o roteamento dos trens especifica as rotas dos trens, o roteamento das cargas trata de definir a sequência de trens a serem utilizados e as operações que deverão ser feitas nos pátios desde a origem até o destino da carga.

Decisões de roteamento e de blocagem estão fortemente inter-relacionadas, uma vez que diferentes grupos de carga (tipo de carga, origem, destino) compartilham um mesmo bloco em partes do trajeto da origem ao destino.

O problema da programação dos trens abrange o roteamento (dimensão espacial) e incorpora a dimensão tempo, o que pode ser feito de forma mais agrega- da (simples definição de frequências dos trens) ou detalhada, através do estabelecimento de uma grade com os horários de chegada e partida para sincronização dos movimentos dos trens nas diversas estações ou pátios ao longo da viagem.

Formados os blocos, aplicam-se políticas, regras e restrições que permitirão alocá-los aos trens programados, processo que constitui o problema da formação de trens, estreitamente ligado aos problemas da blocagem e da programação dos trens.

\subsection{Planejamento integrado da rede de serviços em ferrovias}

Dentre as categorias de modelos para o planejamento do transporte ferroviário citadas por Assad (1980a), um grupo denominado "modelos de redes ferroviárias" refere-se a modelos que buscam integrar atividades de linha (viagens) e pátio, de maneira a gerar decisões mais coordenadas, com vistas ao sistema como um todo. Isto implica em algumas simplificações e um nível mais agregado das informações. Tais modelos são denominados por Newman et al. (2002), como modelos integrados e normalmente focam o nível tático de decisão. Há também modelos táticos específicos para os problemas apresentados (programação, blocagem, roteamento), porém com menor nível de integração das diferentes atividades. Os trabalhos a seguir podem ser considerados como pertencentes a este grupo de modelos, em variados graus de integração:

Crainic et al. (1984) apresentam uma modelagem para o planejamento de frequência dos serviços (trens) aplicado a uma grande ferrovia canadense. O modelo objetiva alocar os recursos para atendimento à demanda de transporte ao menor custo possível, levando-se em conta: o roteamento das cargas e dos trens, as operações de blocagem dos vagões nos pátios, a formação dos trens, além da distribuição das manobras de classificação dos vagões entre os pátios disponíveis. É considerado o congestionamento nas vias de circulação e nos pátios, com efeito tanto nos tempos de processo quanto nos custos. A formulação possui estrutura não linear, inteira-mista, em que a componente inteira refere-se à frequência de cada serviço e a componente não inteira refere-se ao fluxo de carga em cada itinerário. A natureza matemática do modelo e a grande extensão da malha ferroviária analisada inviabilizaram 
uma solução exata, o que motivou o desenvolvimento de uma heurística específica.

Assad (1980b) considera o mesmo tipo de problema e trata o roteamento e formação de trens sob o ponto de vista de fluxo em redes e otimização combinatória, além de fazer uma categorização hierárquica dos problemas ferroviários, conforme a esfera de decisão.

Haghani (1989) combina o problema tático de roteamento e formação de trens ao contexto operacional da distribuição de vagões vazios. O efeito congestionamento é considerado, assumindo-se custos em pátios e de viagem diretamente proporcionais ao fluxo de vagões. Entretanto, são assumidos tempos fixos de viagem entre os terminais.

Keaton (1989) propõe um modelo para definir entre quais pares de terminais haverá trens diretos. Outras decisões consideradas são: a frequência dos serviços; as rotas a serem usadas pelos vagões, dados os trens e terminais disponíveis; como os vagões serão agrupados em blocos nos trens. O modelo utiliza funções lineares de custo, tempos médios de atraso nos pátios e desconsidera congestionamentos.

Marín e Salmerón (1996) tratam o problema de definir as frequências dos serviços e o fluxo de carga em cada itinerário usando a mesma conceituação de Crainic et al. (1984), mas as variáveis de decisão são todas inteiras e são comparados os resultados obtidos por diferentes técnicas heurísticas. Os tempos de viagem são fixos e são estabelecidas restrições para o tamanho dos trens, fluxo de vagões nos terminais e atendimento da demanda. Conclui-se que a natureza matemática do problema aliada à aplicação em grandes malhas ferroviárias exige o uso de heurísticas, mas fica demonstrado que é possível encontrar a solução exata pelo método branch-and-bound no caso de malhas ferroviárias de menor porte.

\subsection{Referências complementares}

Quanto aos custos envolvidos, o custo de capital da frota dimensionada foi quantificado conforme conceitos de engenharia econômica (Hess et al., 1992). O dimensionamento da frota utilizou parte da abordagem proposta por Koo et al. (2004), feita para dimensionamento e roteamento da frota de veículos no transporte de contêineres em um ambiente portuário. Aspectos operacionais e tecnológicos relacionados à diversidade de configurações de trens típicos com uso de tração distribuída e reflexos no consumo de combustível podem ser encontradas em Arakelian (1994), Borba (2001), e Boneti (2007).

\section{A MALHA FERROVIÁRIA UTILIZADA COMO CENÁRIO}

A aplicação desenvolvida focou o fluxo dos trens de minério no sentido exportação. A malha ferroviária utilizada como cenário para este trabalho é real e está representada na Figura 3. O nó 01 representa o terminal portuário aonde chegam os trens para exportação dos produtos carregados em 11 nós de origem, pátios ferroviários aqui chamados pontos de carregamento e situados próximos às minas. Os trechos 05-01 e 09-04 são trechos em via dupla. Os demais trechos são vias singelas. Após descarga no porto, os vagões são novamente reagrupados e distribuídos para novos carregamentos.

Os trens usados no transporte de minério movimentam os vagões em agrupamentos denominados lotes. Todos os lotes possuem o mesmo tamanho, com uma locomotiva e quantidade fixa preestabelecida de vagões, os quais permanecem unidos durante toda a viagem entre pontos de carregamento e descarga. O número de lotes a ser transportado por cada trem varia de um a três, conforme a opção de trem típico escolhida. Daí resultam trens típicos com variados comprimentos, quantidades de locomotivas e posicionamento das mesmas ao longo da composição.

Uma vez carregados os vagões com minério, é pre-

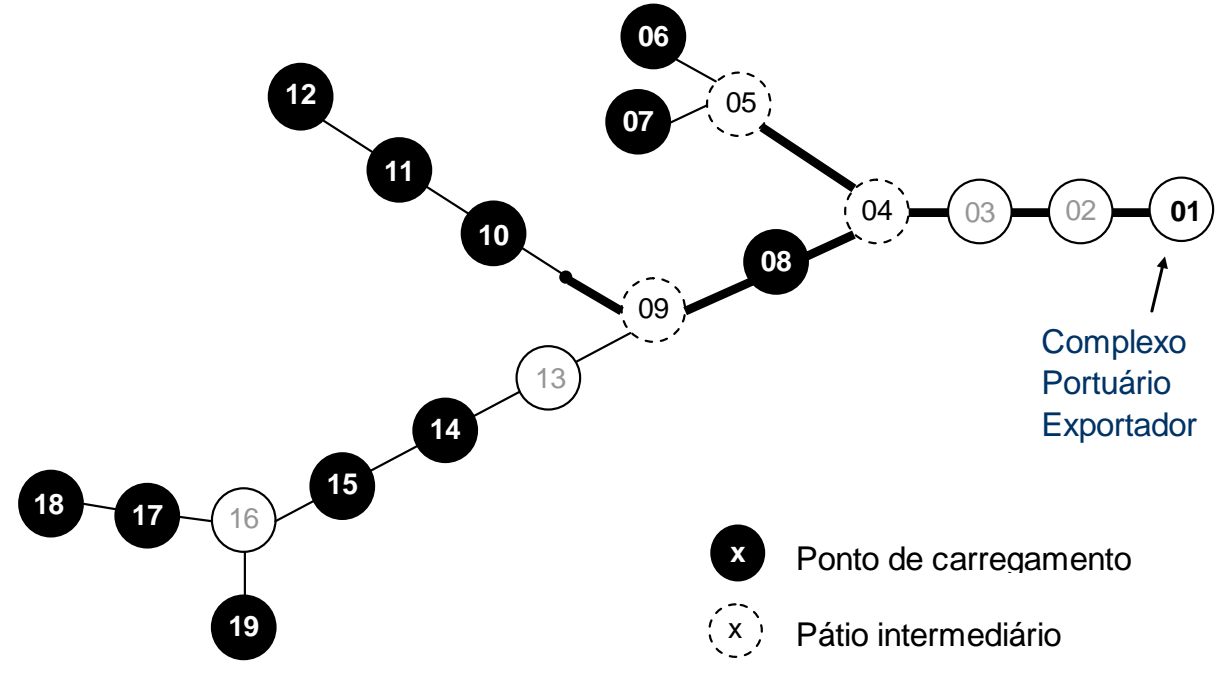

Figura 3. Representação da malha ferroviária estudada 
ciso decidir entre operar trens diretos da origem até o destino ou executar manobras de formação (combinação de trens) que poderão ser feitas nos nós 04,05 e 09 (pátios intermediários), dando origem a trens maiores.

Trens destinados ao terminal portuário (nó 01) possuem sempre dois ou três lotes. As decisões de formação definem o número de trens em circulação (com consequências no nível de congestionamento e tempo de viagem) e afetam principalmente o tráfego no trecho entre os nós 04 e 01 , que concentra todo o fluxo no sentido exportação.

Trens diretos com apenas um lote (muito curtos) para o nó 01 não são praticados, pois aumentariam o número de trens em circulação e percorreriam distâncias muito longas, justamente no trecho mais demandado (do nó 04 ao nó 01). Além disto, demandariam um quadro de maquinistas muito grande. Não são praticados trens diretos com três lotes, pois os pontos de carregamento foram projetados para carregar e liberar trens com no máximo dois lotes. Assim, trens diretos do ponto de carregamento até o terminal portuário, quando praticados, seguem sempre com dois lotes.

As possibilidades para manobras de formação nos nós 04, 05 e 09 são descritas a seguir:

a. nó 05: recebe sempre trens com um lote, podendo formar trens com dois ou três lotes;

b. nó 09: recebe trens com um ou dois lotes, podendo formar trens com dois ou três lotes;

c. nó 04: recebe trens com um ou dois lotes, podendo formar trens com dois ou três lotes.

Trens com três lotes formados nos pátios intermediários (nós 04, 05 e 09) terão sempre como destino o terminal portuário.

É necessária, portanto, uma análise de trade-off entre operar trens longos ou curtos e trens diretos ou não, levando-se em conta o congestionamento em linhas de circulação e nos pátios, além de custos associados ao trem típico, como por exemplo o consumo de combustível. Trens longos exigem mais manobras e tempos de espera nos pátios, mas utilizam recursos tecnológicos que proporcionam maior economia de combustível em relação aos demais trens. Além disto, reduzem o nível de congestionamento nas linhas de circulação na medida em que diminuem a quantidade de trens necessários para uma dada demanda de transporte.

\section{DESENVOLVIMENTO DO MODELO}

O detalhamento do modelo desenvolvido pode ser encontrado em Campos (2009), e constitui uma extensão de escopo e evolução do trabalho de Campos et al. (2008), cuja modelagem abordou a mesma ferrovia brasileira, porém havia assumido tempos de viagem sempre fixos e havia ficado restrita ao tráfego no trecho 01-04 da malha ferroviária. Além disto, a interação de trens nos pátios intermediários não havia sido modelada.

A função objetivo de minimização de custos considerou dois tipos de recursos essenciais ao transporte: 0 material rodante, e o combustível. Tais recursos poderão ser considerados de forma separada ou conjunta. Considerados conjuntamente, os recursos precisam ser traduzidos numa mesma base (monetária) na função objetivo: o custo de capital do material rodante utilizado e o gasto com combustível. Os componentes considerados para a função de minimização de custo são apresentados na Figura 4.

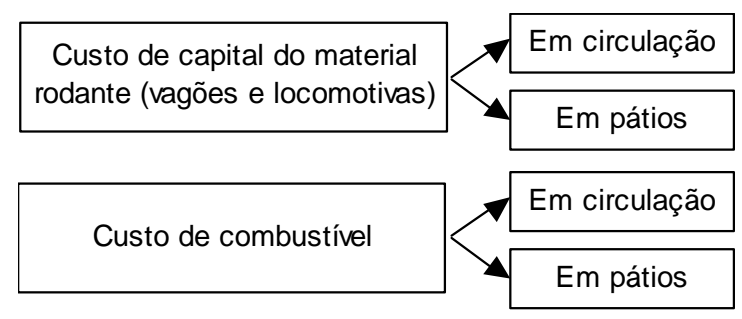

Figura 4. Custos considerados na função objetivo

Para um dado programa mensal de transporte, a minimização dos custos dependerá da frequência mensal dos diversos trens típicos e itinerários. Sendo $S$ o conjunto de serviços oferecidos e $L$ o conjunto de itinerários, deseja-se conhecer:

- $y_{s}$ : vetor da frequência (trens/mês) de cada serviço $s \in S$; e

- $z_{\text {ll }}$ : vetor da frequência (utilizações/mês) de cada itinerário $l \in L$.

Uma vez que a todo itinerário $l \in L$ está associada uma sequência de serviços $s \in S$ com quantidades conhecidas de lotes, a frequência $z_{l}$ do uso de um itinerário dita o volume de carga (total de lotes) por ele escoado ao longo do mês. Um mapeamento dos serviços e itinerários praticados na ferrovia em estudo identificou 46 serviços e 69 itinerários possíveis para os fluxos de minério, sendo que cada serviço foi caracterizado por:

a. um nó de origem do trem (e não da carga);

b. um nó de destino do trem (e não da carga);

c. uma quantidade fixa de vagões ou lotes da origem até o destino do trem;

d. um consumo de combustível típico; e

e. uma rota na rede física (malha viária), unindo origem e destino do trem.

Trata-se de um problema de programação inteira não linear em que a função objetivo é expressa em função de $y_{s}$, mas a variável de decisão é o vetor $z_{l}$, o qual determina $y_{s}$ : 
Minimizar Custo $=f\left(y_{s}\right)$, em que: $y_{s}=f\left(z_{l}\right)$

Sujeito a um conjunto de restrições:

a. atendimento da demanda de cada ponto de carregamento [lotes/mês];

b. restrições de não negatividade e valores inteiros para $y_{s}$ e $z_{l}$;

c. garantia do balanço de massa nos pátios intermediários relacionando $y_{s}=f\left(z_{l}\right)$;

d. número máximo admissível para alguns tipos específicos de trens [trens/mês];

e. limitações na capacidade de tráfego para determinados trechos [trens/mês];

f. limitações na capacidade de manobra dos pátios intermediários; e

g. limitação de frota.

Para a quantificação dos custos de capital (quantificação da frota necessária), foi preciso modelar os tempos gastos pelos trens nas linhas de circulação e nos pátios intermediários.

Nas linhas de circulação, foram adotados tempos fixos de viagem para os trechos singelos. Nos trechos duplicados, onde o tráfego é mais intenso, foram adotados tempos variáveis, modelando-se o efeito congestionamento por teoria das filas e levando-se em conta também o tráfego de outras categorias de trens concorrentes dos trens de minério quanto ao uso da via. O trajeto em via dupla foi subdividido em pequenos subtrechos, cujos tempos de percurso foram tratados como a soma dos tempos de atendimento de vários servidores modelados como sistemas de filas $\mathrm{M} / \mathrm{M} / 1 \mathrm{em}$ série. Um exemplo desta modelagem pode ser visto na Figura 5, onde o tempo de percurso no subtrecho do nó 04 ao nó 03 é obtido a partir do número de trens no sentido exportação.

A modelagem do tempo de permanência dos lotes nos pátios considerou uma penalidade aos trens longos (com três lotes) quando chegam ao terminal por-

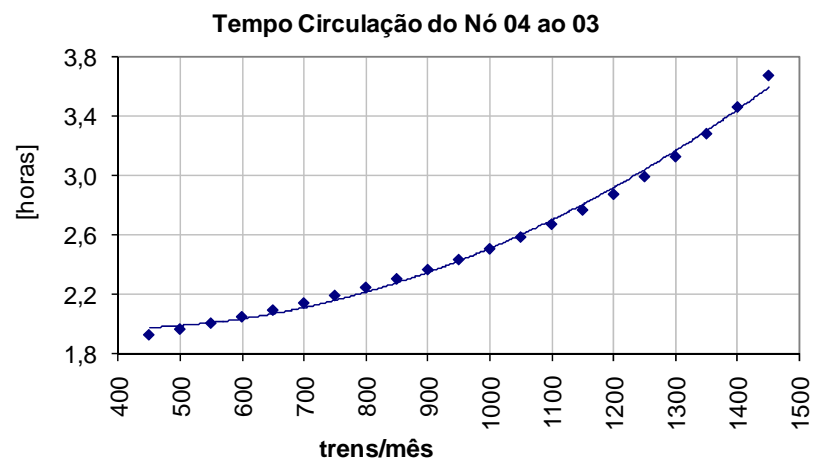

Figura 5. Exemplo de modelagem do efeito congestionamento no tempo de viagem

tuário, por exigirem tempos adicionais nas manobras de chegada. No caso dos pátios intermediários, foram considerados os tempos de manobra (modelados por teoria das filas) e os tempos de espera para acúmulo do número necessário de lotes no trem a ser formado.

Na Figura 6 são mostradas as possibilidades de formação de trens a partir de trens menores e expressões para cálculo dos tempos de espera para acúmulo, em que $\mathrm{Xe}_{\mathrm{j}}$ é o total de trens destinados a um pátio intermediário $j$ qualquer (trens/mês). Nota-se que o tempo de espera para acúmulo $\left(t_{a c}\right)$ é sempre nulo para o último trem que chega. $\mathrm{O}$ intervalo de tempo médio entre trens chegando ao pátio $j$ (expresso em horas) é $720 / \mathrm{Xe}_{\mathrm{j}}$. Esta representação indica que há, por exemplo, três opções (casos II, III e IV) para formação de trens longos (com três lotes): trens com dois lotes que aguardam um segundo trem com um lote (caso II), trens com um lote que aguardam um segundo trem com dois lotes (caso III) ou trens formados a partir de três trens menores com um lote cada (caso IV). No caso IV, por exemplo, a soma dos tempos de espera de cada trem leva ao maior tempo total para acúmulo entre os quatro casos possíveis.

A quantificação do custo de combustível na circulação foi feita a partir do consumo usual conhecido para

\begin{tabular}{|c|c|c|c|c|}
\hline Caso & $\begin{array}{c}\text { 3o Trem } \\
\text { Chegando }\end{array}$ & $\begin{array}{l}\text { 2o Trem } \\
\text { Chegando }\end{array}$ & $\begin{array}{l}\text { 1o Trem } \\
\text { Chegando }\end{array}$ & $\begin{array}{c}\text { Tempo Total para } \\
\text { Acúmulo de Lotes [lotes } \mathrm{x} \text { hora] }\end{array}$ \\
\hline 1 & & $t_{a c}=0$ & $t_{a c}=\frac{720}{X e_{j}} \cdot 1$ & $\begin{array}{c} \\
t_{a c}^{\prime}=\frac{720}{X e_{j}}\end{array}$ \\
\hline II & & $t_{\mathrm{ac}}=0$ & $\begin{array}{c}\square \\
t_{\mathrm{ac}}=\frac{720}{X e_{j}} \cdot 2\end{array}$ & $\frac{\square}{t_{a c}^{\prime \prime}=\frac{720}{X e_{j}} \cdot 2}$ \\
\hline III & & $\begin{array}{c}\square \\
t_{\mathrm{ac}}=0\end{array}$ & $\begin{array}{c}\square \\
t_{a c}=\frac{720}{X e_{j}} \cdot 1\end{array}$ & $\mid>\frac{>}{t_{a c}^{\prime \prime \prime}=\frac{720}{X e_{j}}}$ \\
\hline IV & $\begin{array}{l}\square \\
t_{a c}=0\end{array}$ & $t_{a c}=\frac{720}{X e_{j}} \cdot 1$ & $t_{\mathrm{ac}}=\frac{720}{X e_{j}} \cdot 1+\frac{720}{X e_{j}} \cdot 1$ & $\begin{array}{c}\langle> \\
t_{a c}^{\prime V}=\frac{720}{X e_{j}} \cdot 3\end{array}$ \\
\hline
\end{tabular}

Figura 6. Modelagem dos tempos de espera por acúmulo nos pátios intermediários 
cada trem típico, levando-se em conta o uso de tração distribuída, a distância percorrida, peso rebocado, etc. O gasto com combustível nos pátios foi obtido pelo consumo usual associado às manobras e pela quantidade de manobras efetuadas.

\section{SOLUÇÃO, RESULTADOS E DISCUSSÃO}

Para a solução do problema foram consideradas três abordagens possíveis:

a. implementação de uma heurística específica para esta aplicação;

b. aplicação do algoritmo proposto por Crainic e Rosseau (1986) para a versão genérica do problema; e

c. uso de um aplicativo computacional disponível no mercado.

A primeira alternativa foi descartada por implicar em maior tempo de desenvolvimento e grau de incerteza de sucesso, diante do prazo disponível. A segunda alternativa exigiria a adaptação e implementação de um algoritmo originalmente concebido para solucionar problema muito mais abrangente (multiproduto) e com características diferentes do transporte de minério considerado (cabendo citar, por exemplo, premissas relativas a tamanhos dos trens e modelagem dos tempos em pátio). Implicaria também em maior tempo de desenvolvimento.

Dado o tamanho relativamente pequeno da rede de transporte avaliada e considerando-se o avanço ocorrido nos últimos anos no desenvolvimento de aplicativos computacionais, optou-se pela terceira alternativa, tendo sido escolhido o aplicativo What's Best! ${ }^{\circledR}$ v.10 comercializado pela LINDO SYSTEMS, Inc. O aplicativo utiliza um solver capaz de lidar com problemas não convexos, conduzindo ao ótimo global (Gau e Schrage, 2003). Para solução do problema, utilizou-se um computador com processador de $2,66 \mathrm{GHz}$ e 504 MB de memória RAM.

\subsection{Cenários Analisados}

Dentre as conjunturas possíveis de analisar, considerou-se um mês típico de transporte no ano de 2007 (movimentação média mensal de minério ao longo do ano), com ritmo de transporte ainda intenso, numa condição anterior à crise econômica mundial ocorrida em 2008. Considerou-se um mês típico de safra, com maior incidência de trens cargueiros dedicados ao transporte de grãos, aumentando o congestionamento na malha ferroviária.

Uma demanda mensal totalizando 1.358 lotes de minério destinados ao terminal portuário foi distribuída entre os 11 pontos de origem. Para a demanda acima e o conjunto de restrições mencionado no item 4 , foram consideradas 3 abordagens para a função obje- tivo:

1. minimizar custo de combustível;

2. minimizar custo de frota (custo de capital);

3. minimizar custo de combustível + custo de capital.

Em qualquer abordagem considerada, é importante notar que o custo poderá variar entre um valor mínimo (piso), e um valor máximo (teto). O piso pode ser interpretado como um custo "fixo" indispensável, isto é, por melhor que seja o planejamento, o atendimento da demanda exigirá consumo de tempo, frota e combustível. O teto pode ser interpretado como resultante do pior planejamento em termos de custo. A diferença entre o piso e o teto corresponde à parcela variável do custo, em que a qualidade do planejamento poderá ser percebida.

\subsection{Resultados e Discussão}

A razão entre o piso e o teto indicou uma variação possível de 3\% no caso do custo de combustível e de $10 \%$ no caso da frota. A abordagem 3 ) indicou variação de $6 \%$.

Quando comparadas à abordagem 1, as abordagens 2 e 3 apresentaram redução de pouco mais de $2 \%$ no tempo total de uso dos lotes (pátios + circulação). Tal ganho de tempo equivale a uma redução de 70 vagões na frota necessária para atendimento à demanda. A seguir, será discutido o significado prático e operacional das soluções encontradas para cada abordagem.

Os grafos das Figuras 7 a 9 seguem um mesmo padrão para apresentação dos resultados, com maior detalhamento na Figura 7, visando melhor compreensão. No grafo da Figura 7 está representada a solução obtida para a rede de serviços, no caso da abordagem 1.

A quantidade de lotes ofertados por cada um dos 11 pontos de carregamento (origem), é mostrada no topo da Figura 7, totalizando 1.358 lotes. Os arcos representam os trajetos dos serviços ou trens típicos da solução encontrada. Os trens que devem ser operados entre os nós e suas respectivas frequências são mostrados ao lado dos arcos. Verifica-se, por exemplo, que dos 128 lotes ofertados pelo nó 14, 102 lotes seguirão em 51 trens com dois lotes até o nó 09 (um dos três pátios intermediários); os 26 lotes restantes devem seguir em trens com lote único até o nó 09. Após chegarem ao nó 09, tais trens são combinados com trens provenientes de outros pontos de carregamento, seguindo em trens com três lotes até o nó 01 (destino). Ao todo, são formados 255 trens com três lotes a partir do nó 09. 


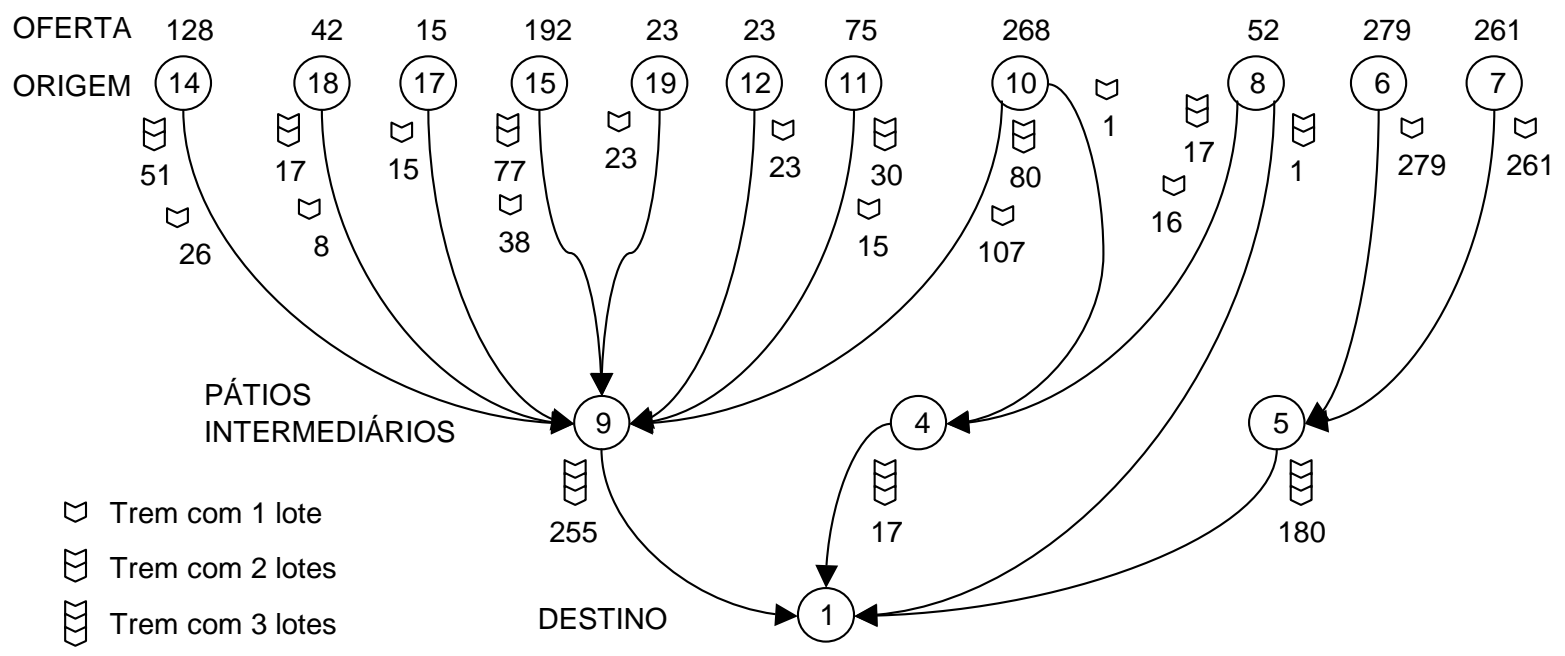

Figura 7. Solução da rede de serviços minimizando o gasto de combustível (abordagem 1)

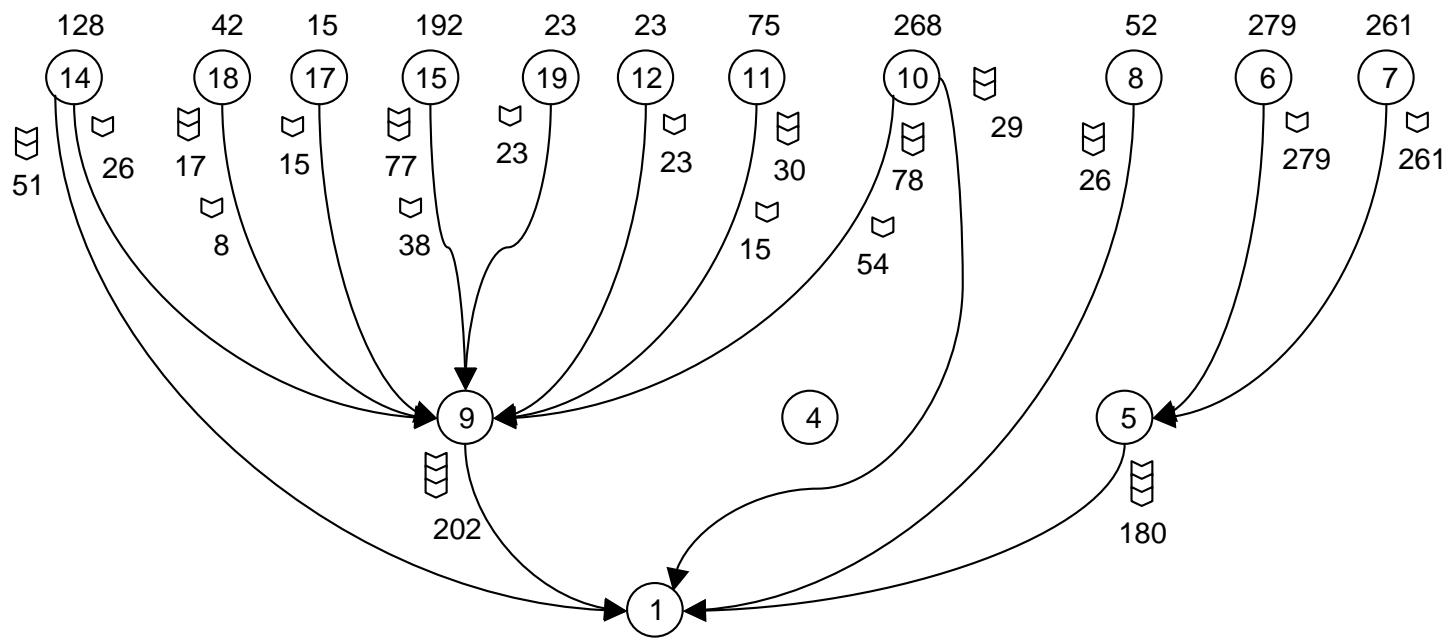

Figura 8. Solução para a rede de serviços minimizando a frota necessária (abordagem 2)

Nota-se claramente o envio quase exclusivo de trens longos ao porto (trens com 3 lotes em tração distribuída), com a incidência de manobras de formação em todos os pátios intermediários. Tal padrão de solução é explicado pela reconhecida eficiência energética desta classe de trens. Houve 1 único trem direto ao porto, partindo do nó 08 e 452 trens longos.

$\mathrm{Na}$ abordagem 2, objetivando-se minimizar a frota necessária, verifica-se pela Figura 8 que o envio de trens longos ao porto caiu de 452 trens para 382 trens (15\% de redução) e deixou-se de utilizar o nó 04 para manobras de formação. A incidência de trens diretos até o porto aumentou de 1 para 106 trens (partindo dos nós 14, 10 e 08).

Com o intuito de avaliar o impacto da modelagem do congestionamento na circulação de trens sobre a solução encontrada, a abordagem 2 foi resolvida fixando-se os tempos de viagem fora dos pátios (o congestionamento na circulação foi desprezado). Com tal premissa, a minimização da frota necessária focou a redução dos tempos de permanência nos pátios e obteve-se a solução apresentada na Figura 9.
Nota-se que o padrão da solução gerada mudou, eliminando-se completamente os trens longos e priorizando-se os trens com 2 lotes. Tais trens podem ser formados nos pátios intermediários com menor tempo de acúmulo em relação aos trens longos, ou podem ser trens diretos do ponto de carregamento até o porto.

Finalmente, a abordagem 3 gerou solução com uma quantidade intermediária de trens longos e trens diretos, quando comparada às abordagens 1 e 2.

\section{CONCLUSÃO}

Foi desenvolvido um modelo com visão integrada das operações ferroviárias em linha e pátio, que facilita o planejamento tático da rede de serviços, levando-se em conta um critério de otimização e condições de contorno. O modelo foi aplicado ao transporte ferroviário de minério de ferro em uma conhecida ferrovia brasileira.

O modelo possui formulação não linear inteira e comprovou-se que as soluções encontradas convergiram muito rapidamente para o valor ótimo global em 


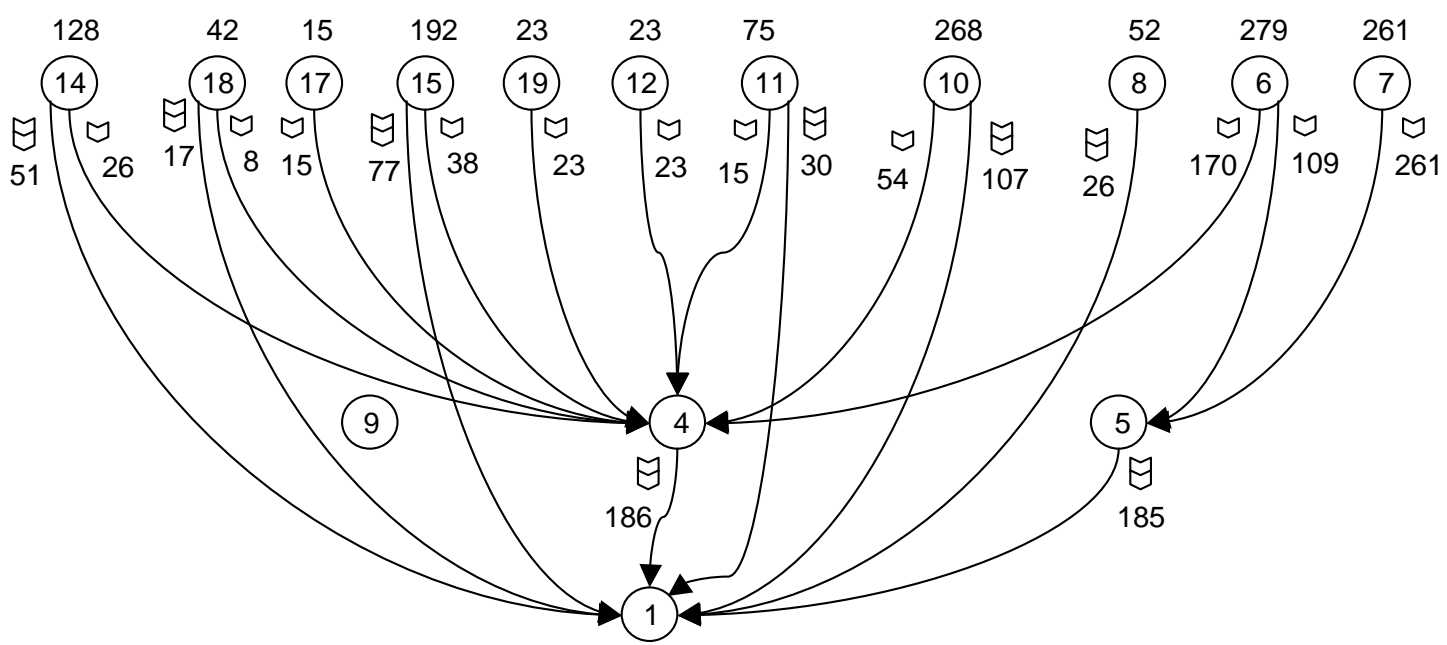

Figura 9. Solução para a rede de serviços minimizando a frota necessária (abordagem 2), desprezando-se o efeito congestionamento na circulação

menos de dez minutos.

O efeito congestionamento foi modelado tanto na circulação quanto nos pátios intermediários, aprimorando significativamente o modelo preliminarmente desenvolvido por Campos et al. (2008) apenas para o trecho principal da ferrovia estudada.

Verificou-se que dadas as inúmeras combinações possíveis para as variáveis de decisão, pode-se admitir para cada abordagem soluções alternativas que apresentem custos semelhantes ou idênticos. Isto foi verificado no processo de busca das soluções, quando foram encontradas respostas distintas com ligeiras variações nas variáveis de decisão conduzindo a valores próximos da função objetivo. Tais respostas guardavam um mesmo padrão geral, no que se refere aos tipos de serviços escolhidos e quantidade de manobras nos pátios.

Soluções alternativas podem ser obtidas a partir de diferentes soluções iniciais ou também pela introdução de restrições adicionais, como por exemplo:

a. Fixando-se a frequência de alguns serviços específicos;

b. Fixando-se limites superiores/inferiores para a frequência de alguns serviços; e

c. Alterando-se os limites para manobras de formação nos pátios intermediários.

Tais avaliações contribuem para uma melhor compreensão do comportamento do sistema analisado e para o planejamento das operações.

Possíveis melhorias no modelo incluem adaptações para o transporte de carga geral, em que os trens possuem maior diversidade de cargas e características diferentes do caso estudado. Esta alteração exigiria o mapeamento de novos itinerários e serviços, além de adequações na modelagem dos tempos gastos em pátios. Outro aspecto a ser aprimorado é a previsão do efeito congestionamento nos tempos de viagem. A modelagem por teoria das filas (modelos $\mathrm{M} / \mathrm{M} / 1$ ) resultou em tempos de viagem sensíveis a variações nas quantidades de trens consideradas. Caso os tempos de viagem tivessem se mostrado menos sensíveis às variações no fluxo de tráfego, as soluções encontradas para minimização da frota necessária tenderiam a reduzir a participação dos trens longos. Tal situação ficou evidenciada nos resultados onde o congestionamento em vias de circulação foi desprezado. Como alternativa, as curvas para previsão dos tempos de viagem poderiam ser obtidas com auxílio de modelos de simulação específicos para análise do tráfego na ferrovia estudada.

Como observação final, vale ressaltar a possibilidade de tratar o problema sob o enfoque da modelagem multiobjetivo, particularmente no caso da abordagem 3, pois é aplicável a situações com diferentes objetivos conflitantes entre si.

\section{AGRADECIMENTOS}

Os autores agradecem pelas contribuições de diversos colaboradores da ferrovia estudada, que ampliaram a compreensão do problema, facilitando a modelagem e conclusões. Agradecimentos também a Mark Wiley, da empresa Lindo Systems, que gentilmente cedeu para este trabalho uma licença temporária do aplicativo computacional escolhido para solucionar o problema, além do apoio no esclarecimento das dúvidas surgidas.

\section{REFERÊNCIAS BIBLIOGRÁFICAS}

Ahuja, R. K.; T. L. Magnanti e J. B. Orlin (1993) Network Flows: Theory, Algorithms and Applications. Prentice Hall.

Arakelian, M. X. (1994) Fuel Conservation from an Operating Viewpoint (rev. ed.): International Association of Railway Operating Officers, $28 \mathrm{p}$.

Assad, A. A. (1980a) Models for Rail Transportation. Transportation Research A: Policy and Practice, v. 14A, p.205-220.

Assad, A. A. (1980b) Modelling of Rail Networks: Toward a Routing/Makeup Model. Transportation Research B: Methodological, v. 14B, p. 101-114.

Boneti, H. J. (2007) Tração Distribuída: Solução em Ferrovias "Heavy Haul”. Revista Ferroviária, ano 68, out., p. 68-70.

Borba, J. L. (2001) Módulo Material de Tração: Pós-Graduação em Engenharia Ferroviária. PUC-MG. Belo Horizonte: [s.n.], 220 p.

Campos, L. B. (2009) Modelo de Otimização para o Planejamento da Rede de Serviços no Transporte Ferroviário de Cargas. 114 f. Dis- 
sertação (Mestrado em Engenharia Civil - Transportes) - Programa de Pós-Graduação em Engenharia Civil, Universidade Federal do Espírito Santo.

Campos, L. B.; M. M. C. Cruz e F. M. Pompermayer (2010) Modelo Integrado de Apoio ao Planejamento da Rede de Serviços no Transporte Ferroviário de Cargas: Aplicação para Transporte de Minério de Ferro. In: Confederação Nacional do Transporte e Associação Nacional de Pesquisa e Ensino em Transporte Transporte em Transformação XIV: Trabalhos Vencedores do Prêmio CNT de Produção Acadêmica 2009. Brasília: Positiva, 220 p. ISBN 97885-99082-10-2

Campos, L. B.; F. M. Pompermayer e M. M. C. Cruz (2008) Modelo de Otimização Aplicado ao Planejamento do Transporte Ferroviário de Carga. Anais do XV Congresso Pan-Americano de Engenharia de Trânsito e Transporte, PANAM, Cartagena de Índias, Disponível em: <http://www.uninorte.edu.co/panam2008/ CDPANAM/index.htm>. Acesso em: 5 abr. 2009. Documento L_037.

Crainic, T. G. (2003) Long-haul freight transportation. In: Hall, R.W. (ed.). Handbook of Transportation Science. 2. ed. [S.l.]: Kluwer, p. 451-516.

Crainic, T. G.; J. A. Ferland e J. M. Rousseau (1984) A Tactical Planning Model for Rail Freight Transportation. Transportation Science, v. 18, n. 2, p.165-184.

Crainic, T. G. e J. M. Rousseau (1986) Multicommodity, Multimode Freight Transportation: a General Modeling and Algorithmic Framework for the Service Network Design Problem. Transportation Research B: Methodology, [s.l.]: v. 20B, p.225-242, 1986.

Gau, C.-Y. e L. E. Schrage (2003) Implementation and Testing of a Branch-and-Bound Based Method for Deterministic Global Optimization: Operations Research Applications. In: Foudas, C. A. e P. M. Pardalos (Ed.) Frontiers in Global Optimization. [S.l.] Kluwer Academic Publishers, p. 145-164.

Goldbarg, M. C. e H. P. L. Luna (2000) Otimização Combinatória e Programação Linear: Modelos e Algoritmos. 2. tiragem. Rio de Janeiro: Campus, $641 \mathrm{p}$.

Haghani, A. E. (1989) Formulation and Solution of a Combined Train Routing and Makeup, and Empty Car Distribution Model. Transportation Research - B: Methodological, v. 23B, p. 433-452.

Hess, G. et al. (1992) Engenharia Econômica. 21. ed. Rio de Janeiro: Bertrand Brasil, $165 \mathrm{p}$.

Keaton, M. H. (1989) Designing Optimal Railroad Operating Plans: Lagrangian Relaxation and Heuristic Approaches. Transportation Research - B: Methodological, v. 23B, n. 6, p. 415-431.

Koo, P. H. et al. (2004) Fleet Sizing and Vehicle Routing for Container Transportation in a Static Environment. OR Spectrum, v. 26, p. 193-209.

Magalhães, P. C. B. (2001) Módulo VII - Fundamentos de logística empresarial: ênfase na atividade transporte. Pós-Graduação em Engenharia Ferroviária. PUC-MG. Belo Horizonte: [s.n.], 203 p.

Marín, A. e J. Salmerón (1996) Tactical Design of Rail Freight Networks. Part I: Exact and Heuristic Methods. European Journal of Operational Research, [s.l.]: v. 90, p. 26-44.

Newman A. M.; L. K Nozick e C. A. Yano (2002) Optimization in the Rail Industry. In: Pardalos, P.M. e M.G.C. Resende (eds.) Handbook of Applied Optimization. New York: Oxford, p. 704-719.

Ragsdale, C. T. (2007) Spreadsheet Modeling \& Decision Analysis: a Practical Introduction to Management Science. 5. ed. [S.1.]: Thomsom South-Western, 820 p. 